\title{
Garantindo direitos: um estudo do sistema socioeducativo em Santa Catarina
}

Pedro Simões'

\section{Resumo}

Em 20 I I- I2, o Sistema Socioeducativo de Santa Catarina organizou uma pesquisa para diagnosticar a garantia dos direitos dos adolescentes em suas unidades. Foram pesquisadas 18 unidades das 24 que compõem o sistema. Os resultados apresentados são sinalizadores do distanciamento existente entre os marcos legais e a vigência institucional dos direitos sociais conferidos aos adolescentes. Foram construídos índices (de educação, de saúde, entre outros) para mensurar a capacidade de cada unidade cumprir o que está estabelecido no Ecriad e no Sinase. Ao final do texto é apresentado um panorama geral do Estado, assim como, são apresentados os resultados específicos para quatro unidades: Casas de Semiliberdade (CSL) de Florianópolis e Chapecó, Plantão de Atendimento Inicial (PAI) e o Centro de Atendimento Socioeducativo Provisório de Criciúma.

Palavras-chave: Adolescente em Privação de Liberdade. Garantia de direitos. Socioeducação.

\section{Introdução}

Em janeiro de 2012, foi promulgada a Lei 12.594, que instituiu o Sistema Nacional de Atendimento Socioeducativo - SINASE. Essa lei, associada ao Estatuto da Criança e do Adolescente (Ecriad) e à Normativa do Conselho Nacional dos Direitos da Criança e do Adolescente (CONANDA) de 2006, marca uma nova fase de consolidaçấo dos direitos da criança e do adolescente privados de liberdade. Esses esforços legais rompem com a visão menorista e consagram, aos adolescentes em regime de internaçáo e semiliberdade, os mesmos direitos daqueles que estáo em liberdade.

Professor associado do Departamento de Sociologia e Ciência Política da Universidade Federal de Santa Catarina (UFSC), Florianópolis (SC), Brasil. Mestre em Serviço Social pela Universidade Federal do Rio de Janeiro (UFRJ) e Doutor em Sociologia pelo Instituto Universitário de Pesquisas do Rio de Janeiro (IUPERJ). Principais publicaçōes: Pescadores de Homens (Degase, Iser: 2010), Filhos de Deus (SDH, Iser: 2010), Garantindo Direitos? (UFSC, 2012).E-mail: josepeneto@gmail.com 
$\mathrm{O}$ presente artigo desdobra, então, quais os direitos a serem assegurados aos adolescentes, a partir, primeiramente, da Normativa do SINASE, instituída pelo CONANDA (2006) e, posteriormente, pela Lei do SINASE, de $2012^{2}$. Em seguida, apresenta os resultados da pesquisa realizada em Santa Catarina com o objetivo de realizar um diagnóstico do Sistema, a fim de observar o quanto as unidades são capazes de garantir os direitos aos adolescentes privados de liberdade. Por fim, será apresentado um rankeamento das Unidades pesquisadas, a partir de um conjunto de indicadores institucionais.

\section{Os Direitos no sistema socioeducativo}

\section{Normativa CONANDA}

A Secretaria de Direitos Humanos - SDH - publicou, em 2006, um conjunto de estudos sobre o Sistema Socioeducativo Brasileiro (COSTA, 2006a, b, c e d). Nesse mesmo ano, foi publicado, pelo CONANDA (Conselho Nacional dos Direitos da Criança e do Adolescente), a Normativa do Sinase (Sistema Nacional de Atendimento Socioeducativo), visando a estabelecer parâmetros para a açáo socioeducativa. Com tais publicaçóes, entretanto, a $\mathrm{SDH}$ buscou estabelecer o que se pretendia com as açóes socioeducativas para os adolescentes privados de liberdade nas Unidades de Internaçáo, Semiliberdade ou Internação Provisória no país.

Esse esforço caracteriza a busca por regulamentar os princípios estabelecidos no Estatuto da Criança e do Adolescente (Ecriad), instituído pela Lei no 8.069, de 13 de julho de 1990. Pautado na Convençáa Internacional dos Direitos da Criança e do Adolescente de 1989, o Estatuto instala, no Brasil, a Doutrina da Proteçáo Integral (VIEIRA, 2008), abolindo o Código de Menores (Lei no 6.697/1979). Fundamentado na Doutrina da Situaçáo Irregular, o Código era dirigido aos "menores" abandonados, infratores, inadaptados, vítimas de violência, considerados em "situação irregular". A mudança de paradigma no plano legal provocou uma extensa transformação nas áreas jurídica, social e política, em razáo da consideraçáo de crianças e adolescentes como sujeitos de direitos especiais, com prioridade absoluta no atendimento, e da observância da condiçáo peculiar de pessoas em desenvolvimento.

2 Para uma visão mais ampla sobre a garantia dos direitos aos adolescentes, ver Miranda (2010) e Klosinski (2006). 
Desde então, com a adoção da Proteção Integral em substituição ao velho modelo da "situaçáo irregular", o trato das circunstâncias envolvendo adolescentes autores de atos infracionais também se transformou. Ainda que enfrentando muitas resistências por alguns segmentos sociais, a passagem da condiçáo de "menor" para a de "cidadáo" e o desenvolvimento de uma nova cultura sobre a criança e adolescente têm sido norteadores do atendimento socioeducativo.

A Normativa do Sinase é fruto de uma construçáo coletiva que ocorreu em todo o Brasil durante muitos anos e que envolveu Governo, Sociedade Civil e especialistas na área. Com o Sistema, que propóe o desenvolvimento de uma açáo socioeducativa sustentada nos princípios dos direitos humanos, criam-se as condiçóes possíveis para que o adolescente em conflito com a lei deixe de ser considerado um problema, um sujeito "irregular", para ser compreendido como uma prioridade social. Tal substituiçáo representou uma opçáo pela inclusáo social do adolescente em conflito com a lei como um sujeito de direitos e náo mais um mero objeto de intervenção, como era considerado no passado (SINASE, 2006).

$\mathrm{Na}$ Normativa, os direitos dos adolescentes são pensados em algumas de suas seçóes. Já nos Princípios (Cap. 3), temos, no Princípio 1, a "garantia dos direitos humanos aos adolescentes", e no 4, "a priorizaçáo do atendimento à criança e ao adolescente, sendo atribuídos a eles todos os direitos previstos no Estatuto da Criança e do Adolescente". Além disso, outros elementos devem ser ressaltados, como a máxima brevidade e a excepcionalidade na restriçáo de liberdade e na execução das medidas socioeducativas (Princípio 7), a inclusáo social do adolescente de modo mais célere possível (Princípio 9), articulando serviços - governamentais e não governamentais - no atendimento às necessidades do adolescentes (Princípio 10), bem como o fortalecimento dos vínculos familiares e comunitários (Princípio 9).

Os demais princípios tratam de questóes relativas à Legalidade (Princípio 5), ao Respeito ao Processo Legal (Princípio 6), à Incolumidade, Integridade Física e Segurança (Princípio 8), ao Atendimento ao Deficiente (Princípio 11), à Municipalização do Atendimento (Princípio 12), à Descentralizaçáo Político-Administrativa (Princípio13), à Gestáo Democrática (Princípio 14), à corresponsabilizaçáo do financiamento (Princípio 15) e à Mobilizaçáo da Opiniāo Pública (Princípio 16). 
O conteúdo da ação socioeducativa não é previsto pelos princípios, mas balizado por eles. Entre esses, alguns se destacam: aos adolescentes em conflito com a lei sáo assegurados os mesmos direitos que aos outros; deve-se buscar e mobilizar todos os recursos governamentais e náo governamentais para a rápida reintegraçáo social, para resignificaçáo de vida e de projetos e perspectivas de futuro; deve-se optar sempre pelas medidas que fortaleçam os vínculos familiares e comunitários; e as medidas devem ser as mais breves possíveis, com a restrição de liberdade somente em último caso. O que se propóe como açáo socioeducativa é a afirmaçáo do adolescente enquanto portador de direitos, superando as visóes paternalistas e tutelares e buscando sua rápida reinserção social.

No capítulo 6 da Normativa do Sinase, estáo estabelecidos os Parâmetros da Gestão Pedagógica no Atendimento Socioeducativo. Entre as diretrizes definidas ali, ressaltam-se: a prevalência da açáo socioeducativa em contraposiçáo aos aspectos sancionatórios; a necessidade de se estabelecerem projetos pedagógicos nas Unidades do Sistema Socioeducativo; participação dos adolescentes na construção, monitoramento e avaliação das açóes socioeducativas; respeito à singularidade dos adolescentes, através de um Plano Individual de Atendimento (PIA $)^{3}$; incorporaçáo de questóes relativas à diversidade cultural, à igualdade racial, de gênero e orientaçáo sexual nos fundamentos teórico-metodológicos dos programas de atendimento socioeducativo; participaçáo da família e da comunidade na experiência socioeducativa.

Essas diretrizes reforçam os princípios que orientam as medidas socioeducativas adicionando alguns elementos importantes - como o respeito náo só aos direitos dos adolescentes, mas à sua individualidade através do PIA e da incorporação das questóes relativas à diversidade cultural, racial, de gênero e de orientação sexual. Além disso, asseguram aos adolescentes a posição de sujeitos, abrindo-lhes a possibilidade de avaliaçáo das medidas socioeducativas (Diretriz 3).

Os princípios e diretrizes da ação socioeducativa são desdobrados em oito eixos principais, a saber: 1 . Suporte Institucional e Pedagógico; 2. Diversidade Étnico-Racial, Gênero e Orientaçáo Sexual; 3. Educação; 4. Esporte, Cultura

3 Conforme o Artigo 52 da Lei SINASE, o PIA é um instrumento de previsão, registro e gestão das atividades a serem desenvolvidas com o adolescentes. 
e Lazer; 5. Saúde; 6. Abordagem Familiar e Comunitária; 7. Profissionalização/ Trabalho/ Previdência; 8. Segurança. Estes oito eixos buscam assegurar, aos adolescentes privados de liberdade, os mesmos direitos daqueles que náo se encontram nesta situação. Nos dizeres da Normativa do Sinase, "além de garantir acesso aos direitos e às condiçóes dignas de vida, deve-se reconhecê-lo como sujeito pertencente a uma comunidade que também deve compartilhar tais valores" (CONANDA, 2006, p. 25).

Portanto, entre as diretrizes gerais que regem a proposta de açáo socioeducativa, há o desenho de um novo olhar para o adolescente e para o desenvolvimento do seu processo nas Unidades de Internaçáo. Esse novo olhar configura-se como uma ética e não como uma política. Isso significa que estáo estabelecidos os parâmetros gerais para ação (ética), mas náo estáo construídos os caminhos que materializam esses mesmos parâmetros (política). Essa diferenciaçáo é pertinente, uma vez que, no processo de implantação dos novos princípios ordenadores do atendimento ao adolescente privado de liberdade, conjugam-se esforços de diferentes atores. Assim, o resultado final que o estrutura como política é a resultante do entendimento que cada ator tem sobre os princípios ordenadores.

A Normativa do Sinase estabelece, entre seus parâmetros para açáo sociopedagógica, uma concepçáo idealizada de adolescente, o qual, segundo esta concepçáo, deve contribuir ativamente para sua formaçáo, tornando-se um cidadáo autônomo, solidário, capaz de decidir de forma fundamentada e de aprender com suas experiências, relacionando-se e integrando-se na comunidade sem reincidir na prática de atos infracionais. Essa visão dificilmente será observada regularmente entre os egressos dos Sistemas.

É preciso que as Unidades sejam capazes de propiciar ao adolescente acesso a direitos e a oportunidades para superação da sua situação de vulnerabilidade e exclusáo, resignificando seus valores, de modo que o seu retorno à vida social seja um reflexo dessa ressignificaçáo. As medidas socioeducativas, nesse sentido, não têm sentido jurídico-sancionatório, mas ético-pedagógico: elas devem transmitir uma nova ética, através de açóes pedagógicas.

\section{A Lei do Sinase}

Logo no seu primeiro artigo, a Lei define que "o Sinase [é] o conjunto ordenado de princípios, regras e critérios que envolvem a execuçáo de medidas 
socioeducativas" (Artigo 1ㅇ, $\$ 1$ ). Portanto, a lei trata dos princípios, das regras e dos critérios para a açáo. O ponto a ser desdobrado refere-se táo somente ao conjunto de direitos atribuídos aos adolescentes privados de liberdade. Estes estâo contidos no item referente às garantias individuais.

No artigo 49, há uma lista com oito garantias principais ${ }^{4}$, as quais são assim discriminadas:

1. Estar acompanhado dos pais ou responsáveis e do defensor em qualquer fase do procedimento administrativo ou judicial;

2. Ser incluído em programa de meio aberto quando náo houver vaga para o cumprimento da medida em privaçáo de liberdade, exceto nos casos de ato infracional cometido mediante grave ameaça ou violência à pessoa;

3. Ser respeitado em sua personalidade, intimidade, pensamento etc.;

4. Peticionar qualquer autoridade ou órgão público, devendo ser respondido em até 15 dias;

5. Ser informado, inclusive por escrito, das normas de organizaçáo e funcionamento do programa de atendimento e das previsóes de natureza disciplinar;

6. Receber informaçóes sobre a evoluçáo de seu plano individual, participando da sua (re)elaboraçáo;

7. Receber assistência integral à saúde;

8. Ter atendimento em creche e pré-escola aos filhos de 0 (zero) a 5 (cinco) anos.

Nesse conjunto de direitos, chama atenção a alteração de sentido que há na legislação em contraposição às Normativas do Sinase. Nestas, a afirmação de direitos era exclusivamente individual e referia-se aos direitos sociais dos adolescentes: lazer, cultura, educação, saúde, entre outros. No entanto, na legislação, os direitos são extensivos à família, incorporando os filhos, e entidades de atendimento. Essa maior abrangência cria a possibilidade de haver

4 Estes direitos tiveram uma redação simplificada. Caso se faça necessário, ver Artigo 49 da Lei 12.594, de 18 de janeiro de 2012. 
menor arbitrariedade nos atos institucionais, já que o adolescente deve estar ciente deles antecipadamente, assim como, pode peticionar contra qualquer autoridade, por escrito ou verbalmente, sobre assuntos que lhe forem pertinentes. Ainda que esses dispositivos demorem a ter repercussóes práticas, eles marcam uma modificaçáo substantiva na concepção dos direitos conferidos aos adolescentes privados de liberdade.

A inclusáo dos direitos relativos à família abrangem o direito à visita dos pais ou responsáveis, parentes, amigos e do cônjuge ou companheiro. Neste último caso, quando exista a comprovação de casamento ou união estável, é também assegurado o direito à visita íntima. A extensáo do direito à visita íntima significa náo somente que o adolescente privado de liberdade tem o direito de continuar relacionando-se com sua família de origem, mas que ele pode também constituir uma família constituída durante a privaçáo de sua liberdade. A extensão do direito à visita íntima significa náo somente que o adolescente privado de liberdade tem uma família de origem, mas que ele pode ter também uma família constituída com um cônjuge e filho(s). Além disso, traz para o debate a questáo da sexualidade dos adolescentes, tema tabu, que necessita ser discutido e demanda formas qualificadas de encaminhamento (MATTAR, 2008).

Ramidoff (2012) salienta ainda, quanto aos direitos individuais do adolescente em conflito com a Lei, que náo se podem ignorar os direitos que estáo elencados e assegurados nos arts. 106 e 109 da Lei Federal n 8069/90, tratando-se exclusivamente do adolescente privado de liberdade, porém não acerca do adolescente em cumprimento de medida socioeducativa.

O referido autor reafirma que é imprescindível a observância dos direitos individuais do adolescente em cumprimento de medida socioeducativa de restriçáo e de privaçáo de liberdade preconizados no Estatuto da Criança e do Adolescente:

No mais, observa-se que, nos casos em que se determina judicialmente ao adolescente o cumprimento de medidas privativas de liberdade - internação e programa (regime) de semiliberdade -, é obrigatório o respeito e o asseguramento de seus direitos especificamente previstos no art. 124 da Lei n. 8.069/90 (RAMIDOFF, 2012, p. II I).

Para além da ampliaçáo dos direitos dos adolescentes, a Lei do Sinase ainda traz outra contribuiçáo significativa para a agenda: o Plano Individual de Atendimento (PIA) passa a ter centralidade na ação socioeducativa. 
Portanto, a partir da promulgaçáo da Lei, as Unidades de Atendimento Socioeducativo devem passar a elaborar o PIA, específico para cada adolescente, em um prazo de 45 dias (Art. 55, parágrafo único). Essa já era uma ação prevista nas normativas do Sinase, entretanto, na Lei, ela ganha nova dimensão com o estabelecimento de prazos. As açóes socioeducativas desenvolvidas nas Unidades devem ser formuladas para o conjunto dos adolescentes que lá se encontram, atendendo às necessidades de cada adolescente em particular.

Esse conjunto de observaçóes não encerra o que a legislação do Sinase tem de novidade em relaçáo às normativas do Sinase. Entretanto, ele é suficiente para indicar o que foi afirmado no final do item anterior: a Normativa do Sinase e a Lei do Sinase indicam princípios e direitos a serem observados pelo legislador e pelos executores das medidas socioeducativas, entretanto, não contêm, em si, metodologias pedagógicas a serem adotadas nas Unidades do sistema socioeducativo. A garantia de direitos não é a ação pedagógica, não há por que confundi-las.

O item a seguir busca, entáo, identificar se as Unidades do Sistema Socioeducativo Catarinense garantem os direitos dos adolescentes. Vale ressaltar, entretanto, que o parâmetro principal, base para a análise, será a Normativa do Sinase e não a Lei 12.594, uma vez que esta ainda náo estava em vigor no momento da pesquisa.

\section{Metodologia}

A pesquisa teve o caráter exploratório, tendo como base a aplicaçáo de survey. O instrumento de pesquisa foi aplicado com os trabalhadores do sistema socioeducativo, abrangendo as categorias profissionais, sendo assim distribuídos: um profissional técnico, um agente de segurança socioeducativo e o gerente/ coordenador da Unidade. A forma de escolha dos entrevistados foi aleatória e as entrevistas ocorreram entre os meses de março e novembro de 2011.

A escolha desses três agentes foi decorrência da posiçáo que estes ocupam nas instituiçóes, sendo os responsáveis pela aplicação das normas e diretrizes institucionais junto aos adolescentes. Dessa forma, a coleta das informaçóes dessas fontes era relevante para a construçáo de um universo representativo de pesquisa.

Os questionários foram aplicados in loco, ou seja, na própria unidade onde os profissionais atuam. Membros da equipe sociopedagógica do Departamento 
de Administração Socioeducativa de Santa Catarina (DEASE/SC), responsável, à época, pelo gerenciamento do Sistema no Estado, foram os agentes que conduziram a aplicaçáo dos questionários ${ }^{5}$.

Os instrumentais foram construídos a partir de blocos de assuntos, combinando perguntas abertas e fechadas. Foram pesquisados os seguintes temas, decompostos em blocos de assuntos: 1. dados gerais da Unidade; 1.1 dados gerais do entrevistado; 1.2 dados específicos da Unidade; 2. condiçáo da internaçáo; 3. estrutura física da Unidade; 3.1. estrutura complementar; 4. estrutura de recursos humanos; e 4. condiçóes técnicas de atendimento, correspondendo a um total de 74 questóes.

As Unidades de atendimento pesquisadas do Sistema Socioeducativo de Santa Catarina foram: as casas de semiliberdade (CSLs) (07): Araranguá, Blumenau, Criciúma, Chapecó, Caçador, Florianópolis e Joinville; os Centros de Atendimento Socioeducativo Provisório (CASEPs) ${ }^{6}$ : Blumenau, Rio do Sul, Criciúma, Tubarão, Caçador, Curitibanos, Joaçaba, Concórdia, Xanxerê e São José do Cedro; e o Plantáo de Atendimento Inicial ${ }^{7}$ - PAI.

É importante salientar que, das Unidades que compóem o sistema catarinense $^{8}, 73 \%$ são administradas através de celebraçáo de convênio entre Estado e entidades da sociedade civil organizadas - ONGS, perfazendo um total de $71 \%$ das vagas (296 em 415 possíveis ${ }^{9}$ ) sob o controle dessas entidades (dados de março/2011 fornecidos pelo DEASE). Além disso, ao observar a distribuição das Unidades do sistema socioeducativo entre as ONGs, é possível verificar que 16 diferentes instituiçóes administram as Unidades com parceria técnico-financeira com o DEASE e mais da metade dessas instituiçóes têm alguma vinculação religiosa e espiritualista.

Dessa forma, o sistema socioeducativo catarinense apresenta uma diversidade que vincula tipos de gestáo (pública/privada), tipos de internaçáo (internaçáo,

50 questionário é excessivamente extenso para ser adicionado como anexo deste trabalho. Ele comportou, praticamente, 70 perguntas. Informações mais detalhadas a seu respeito, bem como uma análise dos outros itens pesquisados, podem ser encontrados em Simões (20/2).

6 Os CASEPs, embora sejam unidades dedicadas à internação provisória, ou seja, limitada a 45 dias, eles funcionam também como unidades de internação. Quando há apenas a internação provisória, os adolescentes permanecem acautelados, mas não estão ainda cumprindo medida socioeducativa.

7 No PAl, além do atendimento inicial, funcionam também a unidade de internação feminina e masculina e a internação provisória masculina.

8 As seis que não foram contempladas na pesquisa foram: CASEP de Itajai; CASEP de Joinville; CASE e CASEP de Chapecó; CASE e CASEP de Lages.

9 Dados relativos à época da pesquisa. 
internação provisória, semiliberdade), tipo de tratamento (Socioeducativo ou Socioterapeutico) e vínculo religioso ou espiritualista (com ou sem vínculo).

Das dezoito (18) Unidades onde a pesquisa foi realizada, somente uma (01) é administrada diretamente pelo Governo Estadual, o PAI. As demais Unidades, dezessete (17), sáo administradas, indiretamente, pelas Organizaçôes da Sociedade Civil. Assim, esse diagnóstico revela a capacidade das entidades que se comprometeram com o Estado de prestarem serviços socioeducativos. A ausência de maiores informaçóes das outras Unidades administradas pelo Governo foca o "diagnóstico" nas agências não governamentais que atuam na gestáo socioeducativa.

Os registros da entrevista realizada com os três agentes institucionais pesquisados foram reduzidos a um único registro por cada uma das dezoito Unidades socioeducativas. Esse registro único foi obtido através da média entre as respostas positivas (resposta valor 1 ) ou negativas (respostas com valor 0 [zero]) dos agentes. Assim, quando a média foi 0 (zero) a resposta dos agentes institucionais foi considerada de "concordância negativa"; quando a média foi 1 (um), a posiçáo dos agentes institucionais foi de "concordância positiva"; quando a média obtida foi de um valor maior que zero e menor que um, isso significa que houve "discordância" entre os agentes institucionais.

Quando houve concordância, independentemente se positiva ou negativa, esta resposta expressa que náo há dúvida, entre os agentes institucionais, sobre o ponto pesquisado. Portanto, esses resultados sáo decorrentes de "posiçóes institucionais", seja para validação ou negaçáo do que foi investigado. A discordância, entretanto, evidencia a existência de uma inconsistência na informação. Os principais agentes que operam o sistema náo são capazes de dar a mesma reposta sobre questóes como a existência de serviços (escolarizaçáo, cursos profissionalizantes, entre outros) e direitos (acesso à justiça, à família, entre outros) aos adolescentes. Portanto, a discordância revela uma fragilidade na capacidade de atendimento aos adolescentes internados. Essa característica pode ser entendida ainda como uma ausência de completa institucionalizaçáo do que está sendo observado.

O processo de "institucionalizaçáo" significa a designaçáo de competências a agentes institucionais, a incorporação da atividade à rotina da Unidade, o estabelecimento de parâmetros materiais para o seu desenvolvimento (onde ocorrerá, como ocorrerá etc.), entre outras formalidades. Assim, a incapacidade de haver concordância entre os representantes institucionais revela a não institucionalização da atividade observada. 
Por outro lado, a atividade pode ocorrer, mesmo sem estar plenamente institucionalizada. Nesse caso, entretanto, sua vigência ocorre de forma desestruturada, assistemática, por conveniência, o que acarreta a discordância entre os representantes institucionais. A discordância revela que a garantia dos direitos dos adolescentes ainda náo se encontra institucionalizada, ficando na dependência da boa vontade e do favor dos agentes institucionais.

Pelas razóes acima expostas, a análise que se segue se concentra basicamente nas "concordâncias positivas". Elas são tidas aqui como indicadoras da institucionalização das práticas e açóes observadas.

Segundo a Normativa do Sinase (2006), os direitos a serem atendidos estão estruturados nos Eixos: 1. Educação, 2. Esporte, Cultura e Lazer, 3. Saúde, 4. Abordagem Familiar e Comunitária, 5. Profissionalizaçáo, Trabalho e Previdência, 6. Segurança.

A análise realizada, neste trabalho, seguiu uma orientaçáo inspirada na Normativa do Sinase, incorporando algumas modificaçóes: o eixo "esporte, cultura e lazer" foi desmembrado, pois se entende que cada uma das atividades acarreta um direito de per si; o mesmo ocorreu com o eixo "abordagem familiar e comunitária", sendo desdobrado em "acesso à família/recebimento de visitas" e "saída da Unidade".

Assim, seráo observados os seguintes direitos: Escolarizaçáo, Trabalho/ Profissionalização, Cultura, Lazer, Esportes, Assistência Religiosa, Acesso à Família/Recebimento de Visitas, Acesso à Justiça, Acesso à Saúde (Necessidades Especiais, Drogas e Doença Mental) e Saída da Unidade.

\section{Garantia de direitos ${ }^{10}$}

A partir dos dez direitos analisados, foi construído um índice único que revela a capacidade de atendimento das Unidades aos direitos dos adolescentes. Antes, porém, de apresentar os resultados, sáo necessários alguns esclarecimentos metodológicos. Primeiro, os resultados abaixo, embora revelem um quadro grave de desrespeito ao direito dos adolescentes, apresentam-se, no mencionado índice, de forma conservadora, ou seja, sempre que possível, considerou-se que os direitos estavam garantidos.

10 Outras avaliações sobre a aplicação de medidas socioeducativas podem ser encontradas em Volpi (20II) e Zamora (2005) 
Além disso, foi considerado táo somente se as Unidades eram capazes de prover os serviços (atendimento aos direitos) sem ser possível identificar a qualidade do atendimento. A estimaçáo conservadora ocorreu também porque alguns itens foram desconsiderados, visto que náo eram contemplados por nenhuma das Unidades. Quando, entre os elementos de um item, era possível considerar algum aspecto atendido por uma ou mais Unidades, este foi priorizado ante os itens náo contemplados.

Por último, mas não menos importante, cabe considerar que, nos casos da Educaçáo e Saúde, foram construídos índices próprios, os quais foram inseridos diretamente na soma para obtençáo do valor final. Assim, para a construçáo do índice, foram consideradas as respostas de concordância positiva para os itens:

1. Escolarizaçáo - índice de escolarizaçáo, contemplando os seguintes elementos: 1. Prestaçáo de serviços de escolarizaçáo aos adolescentes, independentemente se direta ou indiretamente; 2. Na Unidade há uma Escola em funcionamento?; 3. Há salas de aula em funcionamento?; 4. Há biblioteca em funcionamento?; 5. Há recursos audiovisuais em uso?;

6. Há acesso à informática?;

2. Profissionalização - se há, na Unidade, o referido curso;

3. Cultura - se a Unidade promove atividades culturais;

4. Lazer - se a Unidade promove atividades de lazer, independentemente da existência de local apropriado para a atividade;

5. Esporte - se a Unidade promove atividades de esporte, independentemente da existência de local apropriado para tanto;

6. Assistência Religiosa - se a Unidade promove atividades de assistência religiosa, independentemente da existência de local apropriado para a atividade, sem se considerar se a liberdade religiosa dos adolescentes é respeitada;

7. Visita Familiar - se a Unidade permite a visitaçáo familiar (não foi considerada a permissáo para visita íntima, pois essa atividade náo é contemplada por nenhuma Unidade);

8. Acesso à Saúde - índice de acesso à saúde, contemplando os seguintes itens: se a Unidade disponibiliza serviços 1. de enfermagem; 2. médico; 
3. dentista; 4. psiquiátrico; 5. psicopedagógico; 6. se há acessibilidade nas Unidades; 7. se algo é realizado pelos dependentes químicos, ainda que o tratamento esteja restrito à administraçáo de medicamentos; 8. para os casos de saúde mental, se há encaminhamento para o atendimento na Unidade de saúde do município;

9. Acesso à Justiça - se, na Unidade, há um núcleo jurídico que dê apoio aos adolescentes;

10. Saída da Unidade - se sáo previstas atividades fora da Unidade como forma de integraçáo comunitária dos adolescentes.

Cada um dos dez direitos foi pontuado entre 0 (zero) e 1 (um), sendo zero para os casos em que as equipes concordavam negativamente, discordavam sobre a provisão dos serviços (atendimento aos direitos) ou discordavam, e 1 (um) para a concordância positiva. Nos casos do direito à educaçáo e à saúde, os valores inseridos variaram entre 0 e 1 , havendo valores fracionados. Assim, o Índice de Direitos consiste na soma dos dez itens, variando, assim, entre 0 e 10 . Vejam-se os resultados abaixo:

Tabela I - Índice de Direitos, segundo Unidade do Sistema Socioeducativo

\begin{tabular}{lcc}
\hline Unidades & Índice Geral & Grupos \\
\hline CSL Florianópolis & 7,5 & 4 \\
CSL Joinville & 6,5 & \\
\hline CASEP Caçador & 5,4 & \\
CSL Araranguá & 5,3 & \\
CASEP Criciúma & 4,5 & 3 \\
CASEP Concórdia & 4,5 & \\
CSL Criciúma & 4,3 & \\
CASEP Blumenau & 4,0 & \\
\hline CASEP Rio do Sul & 3,8 & \\
CASEP São José do Cedro & 3,5 & \\
CASEP Curitibanos & 3,3 & \\
CASEP Joaçaba & 3,3 & \\
CASEP Xanxerê & 3,3 & \\
CSL Blumenau & 3,0 & \\
CASEP Tubarão & 2,5 & \\
CSL Concórdia & 2,0 & \\
\hline PAI & 1,3 & \\
CSL Chapecó & 1,1 & \\
\hline
\end{tabular}

Fonte: Simões, 2012 
A capacidade de mudança do modelo punitivo para o de proteçáo integral e socioeducaçáo depende, em "primeira instância"11, exatamente, da capacidade de as Unidades passarem a atender aos direitos dos adolescentes. Assim, qualquer violaçáo de direitos acarreta uma punição, pois, além de estarem privados de liberdade, os adolescentes deixam de poder ter acesso a um direito específico. Por outro lado, a cultura de culpabilizaçáo dos indivíduos e de puniçáo aos infratores da lei ainda é muito presente em nossa cultura. Por isso, os resultados acima devem ser entendidos como um processo, uma luta para a consolidaçáo de outro paradigma no tratamento dos adolescentes. Algumas Unidades encontram-se mais próximas dessa consolidação, outras ainda muito distantes.

As Unidades de PAI (única Unidade sob administraçáo governamental) e CSL Chapecó são as que estão mais distantes de uma gestáo socioeducativa. As Unidades de CASEP Rio do Sul, CASEP Sáo José do Cedro, CASEP Curitibanos, CASEP Joaçaba, CASEP Xanxerê, CSL Blumenau, CASEP Tubaráo e CSL Concórdia formam um segundo grupo em que há de 2 a 4 direitos garantidos, portanto, com um cobertura ainda baixa. Mais da metade das Unidades encontram-se nesses dois grupos iniciais, demonstrando que o Sistema Socioeducativo catarinense ainda apresenta muitas fragilidades no atendimento ao adolescente infrator.

Um terceiro grupo é composto por CASEP Caçador, CSL Araranguá, CASEP Criciúma, CASEP Concórdia, CSL Criciúma e CASEP Blumenau. Nesses casos, a cobertura dos direitos varia entre 4 e 6 , constituindo-se um grupo intermediário.

O último grupo, constituído por somente duas Unidades (CSL Florianópolis e CSL Joinville), é o que está mais próximo de ter uma atuaçáo socioeducativa, pois contemplam entre 6 e 7 direitos dos adolescentes.

Educação e saúde foram mensuradas constituindo-se como índices próprios. Apresento, abaixo, a distribuição desses índices, conforme o atendimento destes pelas unidades.

II Em "segunda instância", deve-se considerar também a forma e a qualidade do atendimento. Esses dois aspectos não puderam ser observados na pesquisa e são fundamentais para que a concepção de socioeducação tenha algum sentido. Poderíamos ainda considerar, "em terceira instância", a formulação de um plano de atendimento socioeducativo para o trabalho desenvolvido na Unidade como um todo e para cada um dos adolescentes em particular (PIA). 
Tabela 2 - Índice de Escolaridade, segundo Unidade do Sistema Socioeducativo

\begin{tabular}{llc}
\hline Unidade & $N$ & Índice de Escolaridade \\
\hline CASEP Criciúma & 4 & 0,67 \\
CASEP Rio do Sul & 4 & 0,67 \\
CASEP Concórdia & 3 & 0,50 \\
CASEP Tubarão & 3 & 0,50 \\
CASEP Curitibanos & 2 & 0,33 \\
CASEP São José do Cedro & 2 & 0,33 \\
CSL Joinville & 2 & 0,33 \\
CASEP Caçador & 1 & 0,17 \\
CASEP Joaçaba & 1 & 0,17 \\
CASEP Xanxerê & 1 & 0,17 \\
CSL Araranguá & 1 & 0,17 \\
CSL Criciúma & 1 & 0,17 \\
CSL Florianópolis & 1 & 0,17 \\
CASEP Blumenau & 0 & 0,00 \\
CSL Blumenau & 0 & 0,00 \\
CSL Chapecó & 0 & 0,00 \\
CSL Concórdia & 0 & 0,00 \\
PAI & 0 & 0,00 \\
\hline
\end{tabular}

Fonte: Simões, 2012

A tabela 2 demonstra que nenhuma das Unidades contém todos os recursos educacionais para os adolescentes. As Unidades CASEPs de Criciúma e Rio do Sul são as que mais os disponibilizam, enquanto outras cinco Unidades (quase 30\%) náo oferecem nenhum dos recursos possíveis para a garantia do direito dos adolescentes a permanecerem estudando durante o período de restriçáo e privaçáo de liberdade. 
Tabela 3 - Índice de Atendimento à Saúde, segundo Unidade do Sistema Socioeducativo

\begin{tabular}{lc}
\hline Unidade & Índice de Atendimento à Saúde \\
\hline CASEP Criciuma & 0,88 \\
CSL Florianópolis & 0,38 \\
CASEP Caçador & 0,25 \\
PAI & 0,25 \\
CASEP Joaçaba & 0,13 \\
CASEP Rio do Sul & 0,13 \\
CASEP São José do Cedro & 0,13 \\
CASEP Xanxerê & 0,13 \\
CSL Araranguá & 0,13 \\
CSL Chapecó & 0,13 \\
CSL Criciúma & 0,13 \\
CSL Joinville & 0,13 \\
CASEP Blumenau & 0,00 \\
CASEP Concordia & 0,00 \\
CASEP Curitibanos & 0,00 \\
CASEP Tubarão & 0,00 \\
CSL Blumenau & 0,00 \\
CSL Concórdia & 0,00
\end{tabular}

Fonte: Simões, 2012

Os resultados demonstram que, apenas em CASEP Criciúma há atendimento à saúde dos adolescentes. Nos demais casos, das oito possibilidades consideradas, as Unidades apenas contemplam, no máximo, 3 delas, sendo que, em seis Unidades, não há acordo entre os técnicos sobre a viabilização de, ao menos, um dos procedimentos considerados.

O gráfico abaixo mostra como cada uma das Unidades atende aos direitos à educação e saúde dos adolescentes. 
Gráfico 1 - Índice de Saúde, segundo Índice de Escolaridade

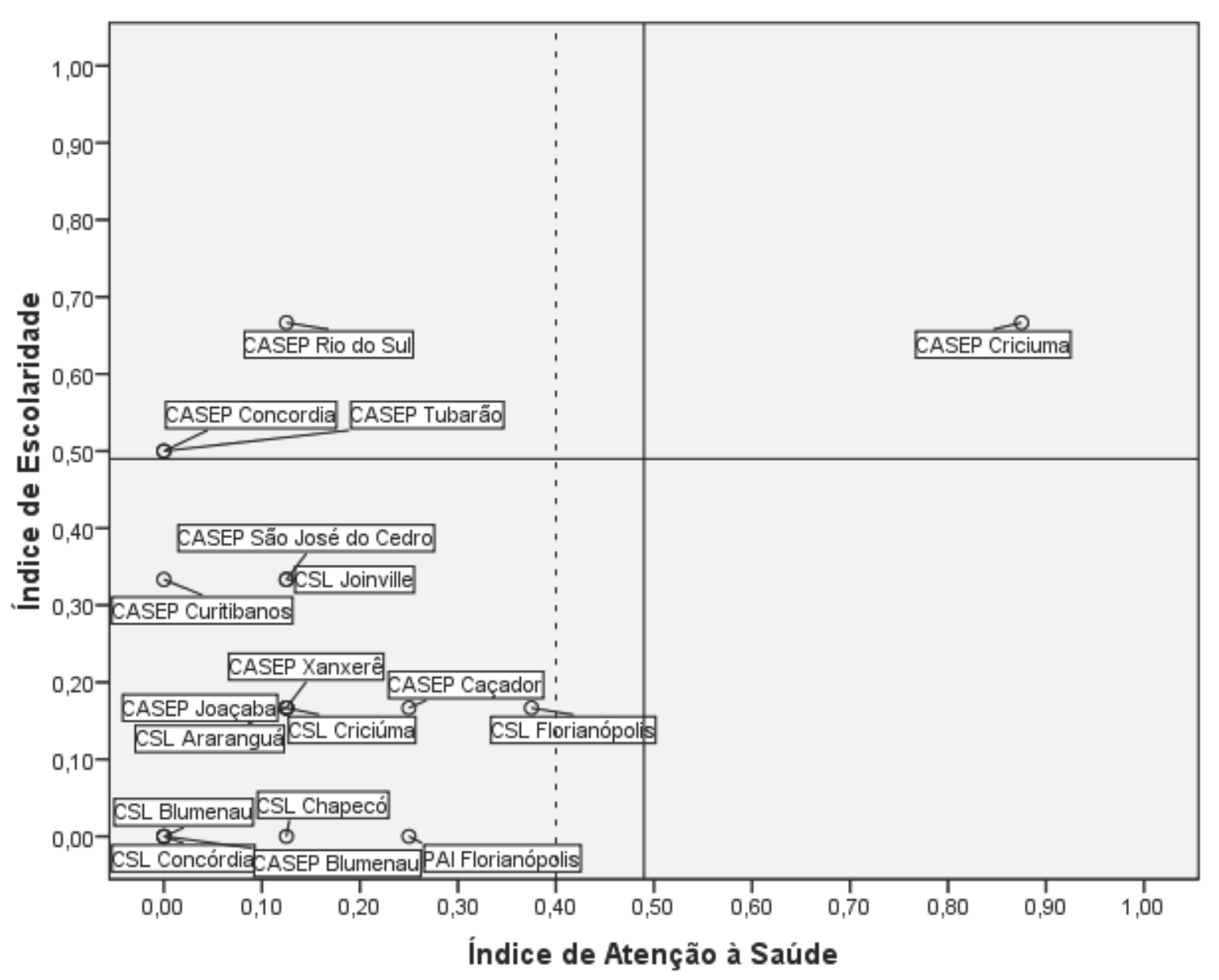

Fonte: Simões, 2012

À exceção de CASEP Criciúma, em todos os demais casos, a capacidade de atendimento à saúde náo chega a $40 \%$ do estimado (ou índice 0,4 ). Os CASEPs de Rio do Sul, Concórdia e Tubaráo ainda conseguem ter um índice de escolaridade igual ou superior a 0,5, atendendo a 50\% do pesquisado. Em todos os demais casos, o atendimento ao direito de educaçáo e de saúde, conjuntamente, dos adolescentes é baixo (menor ou igual a $40 \%$ do estimado). 


\section{Outros Índices}

A pesquisa estabeleceu ainda outros índices, a saber: índice de integraçáo em rede ${ }^{12}$; índice de organizaçáo do atendimento ${ }^{13}$; índice da presença de profissionais ${ }^{14}$; e índice de utilização de instrumentos profissionais ${ }^{15}$.

Assim, foi realizada uma análise fatorial com todos os cinco índices construídos, como pode ser observado no gráfico abaixo:
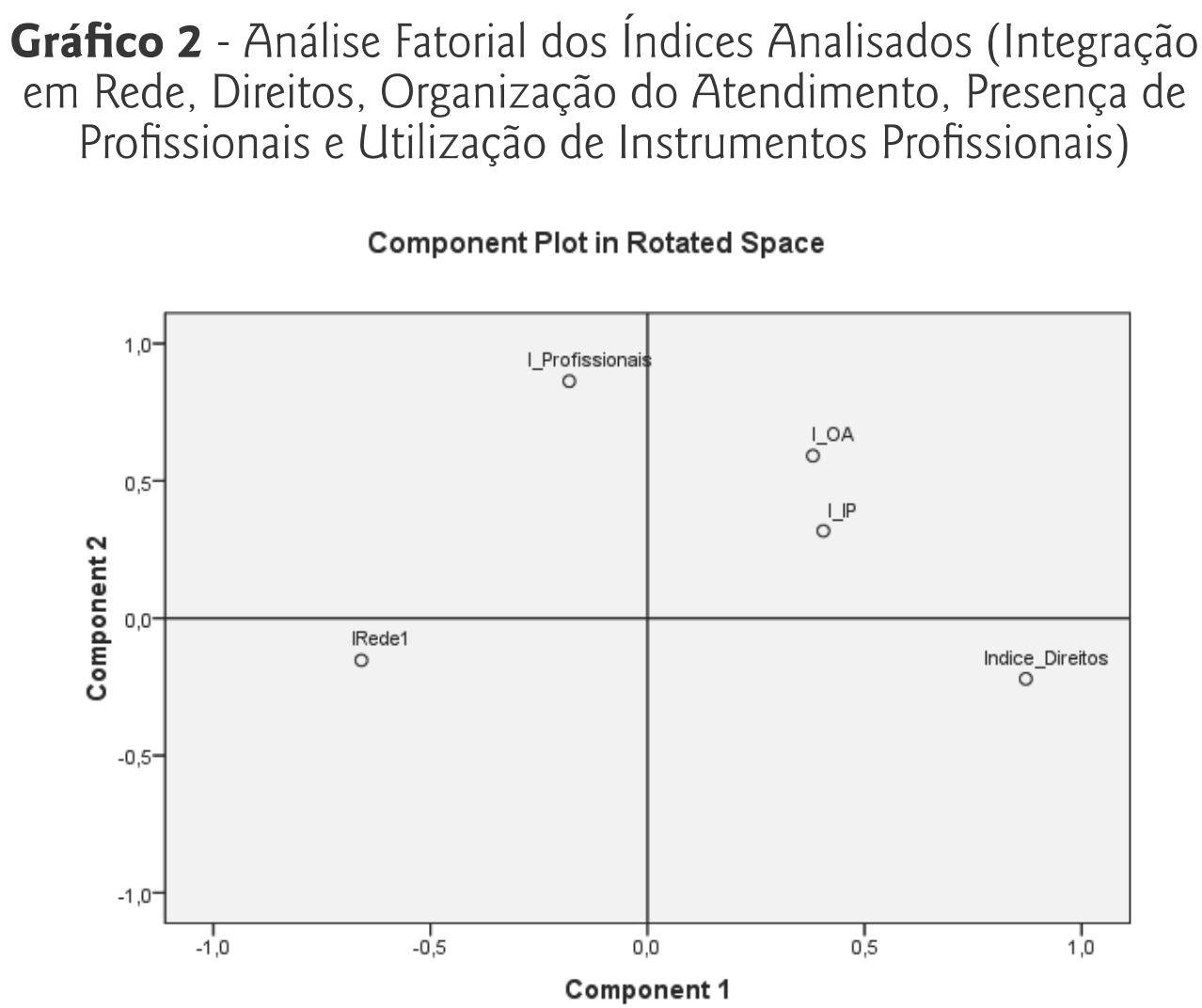

Fonte: Simões, 2012

12 Identificava se a Unidade estava integrada com as seguintes instituições: Centro de Saúde local, Ministério Público, Poder Judiciário, Sistema Educacional, Centros de Atenção Psicossocial (CAPs), Hospital, Conselho Tutelar, Centro de Referência de Assistência Social (CRAS), Centro de Referência Especializado de Assistência Social (CREAS) e Conselho Comunitário de Segurança (CONSEG).

13 Este índice contemplava os itens: reunião, planejamento, discussão de caso, comissão de disciplina, elaboração de proposta coletiva, integração, elaboração do PIA e outros.

14 O ponto de partida para a construção deste indicador foi a existência da "equipe minima", tal como estabelece a Normativa do Sinase.

15 Dentre estes estão: Regulamento Interno, Ficha de Admissão, Projeto Político-Pedagógico, Relatórios Situacionais, PIA, Recibo de Pertences, Ficha de Acompanhamento, Pareceres Técnicos, Ficha de Desligamento e Petições para Saída Temporária. Manual de Normas de Procedimentos. Termo dos Documentos aos Familiares, Manual de Sanções Disciplinares e Manual do Visitante. 
O primeiro componente (1) é aquele em que a integraçáo em rede está em oposição ao índice de direitos. Este resultado revela, em verdade, "modelos" de viabilização dos direitos, ora em rede, ora por meios próprios à Unidade. Ao observar o componente 2, o que mais se sobressai é o índice de presença profissional. Sua variaçáo revela a presença maior ou menor de profissionais nas Unidades.

Os indicadores de organizaçáo do atendimento e de utilizaçáo dos instrumentos profissionais estáo em uma posiçáo equidistante ao índice de direitos (componente 1) e ao índice de profissionais (componente 2). Este resultado significa que a viabilizaçáo de mais direitos pela Unidade está relacionada à capacidade das equipes de maior organização do trabalho e de utilização dos instrumentos profissionais; além disso, quando há mais profissionais nas Unidades, os trabalhos das equipes também tendem a ser mais organizados e a utilizar maior número de instrumentos.

Gráfico 3 - Análise dos Componentes Principais (Padronizados), segundo Unidades do Sistema Socioeducativo

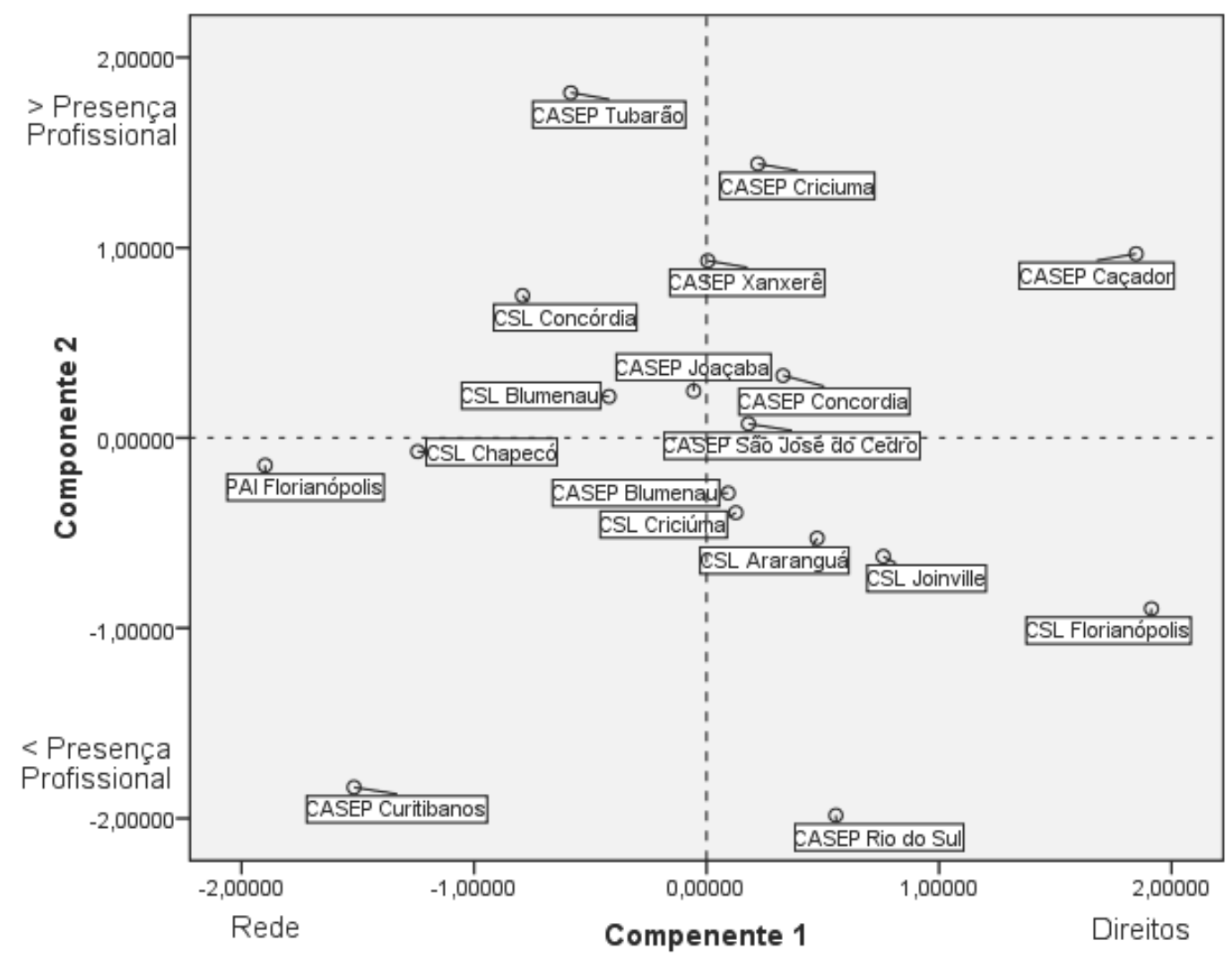

Fonte: Simões, 2012 
O Gráfico resume a posiçáo de cada Unidade em relação aos dois componentes considerados. Analisando o gráfico da esquerda para a direita (linha horizontal, Componente 1), estáo as Unidades que váo da maior integraçáo em rede (PAI e CASEP Curitibanos) à maior garantia de direitos (CASEP Caçador e CSL Florianópolis). Quanto mais ao centro (CASEP Joaçaba, por exemplo), maior a indefinição entre um ou outro "modelo".

Analisando o gráfico de cima para baixo (linha vertical, Componente 2), estáo as Unidades com maior presença de profissionais (CASEP Tubaráo) para as de menor presença (CASEP Rio do Sul). Vale considerar que os índices de organizaçáo do trabalho e utilizaçáo dos instrumentos profissionais sáo correlacionados positivamente tanto com o componente 1 quanto com o 2. Assim, as Unidades que se encontram no primeiro quadrante (sentido horário) e mais próximas das extremidades compartilham, além das características dos componentes 1 e 2 (a depender do caso), valores altos para ambos os índices. Este é o caso tanto de CASEP Caçador quanto de CASEP Criciúma.

A maior parte das Unidades, entretanto, não se encontra nas extremidades do gráfico, mas perto do seu ponto central. Sáo Unidades que, por apresentarem valores mais próximos das médias, tornam-se difíceis de ser classificadas "para mais" ou "para menos".

\section{Considerações finais}

Nesta parte final do trabalho, é apresentado um ranking institucional. Nele, é possível identificar a posiçáo de cada uma das Unidades estudadas, conforme a garantia de direitos aos adolescentes, bem como, da capacidade de atendimento institucional.

A tabela 4, denominada de "síntese", mostra o resultado de cada um dos índices analisados, ao longo da pesquisa, segundo as Unidades do sistema socioeducativo. Assim, na primeira célula da tabela, encontra-se o valor do índice de integraçáo em rede para o CSL Florianópolis $(0,3)$.

Os valores entre parênteses que se encontram nas células representam o ranking da Unidade no índice determinado pela coluna. Dessa forma, no caso de CSL Florianópolis, na primeira coluna, o índice 0,3 foi o sexto maior identificado; já o de CASEP Curitibanos $(0,8)$ foi o maior índice identificado entre as Unidades no que tange à integração em rede. 
Os valores entre parênteses que se encontram na linha de títulos indicam o número de níveis do ranking estabelecido em cada índice. O resultado de CSL Florianópolis, para a integraçáo em rede, é o sexto, entre sete níveis possíveis. Como pode ser visto, cada um dos índices mensurados propiciou um intervalo de ranking específico. $\mathrm{O}$ tamanho do intervalo demonstra o quanto as Unidades se diferenciam (dispersam) entre si, em cada índice. Quanto menor o tamanho do intervalo, mais semelhantes as Unidades sáo no índice estudado. Este é o caso, por exemplo, do índice de presença profissional, com apenas quatro níveis.

Por último, a tabela foi ordenada pelo ranking do índice de direitos (coluna 7). A razáo desse ordenamento reside no fato de que é possível observar, a partir da Unidade com melhor ranking de garantia de direitos, quais os demais índices para cada Unidade.

Tabela 4 - Síntese

\begin{tabular}{lcccccccc}
\hline Unidade & $1(7)$ & $2(4)$ & $3(7)$ & $4(5)$ & $5(5)$ & $6(5)$ & $7(15)$ \\
\hline CSL Florianópolis & $0,3(6)$ & $0,4(3)$ & $0,3(5)$ & $0,5(2)$ & $0,2(4)$ & $0,4(2)$ & $7,5(1)$ \\
CSL Joinville & $0,4(5)$ & $0,4(3)$ & $0,3(5)$ & $0,3(4)$ & $0,3(3)$ & $0,1(4)$ & $6,5(2)$ \\
CASEP Caçador & $0,2(7)$ & $0,4(3)$ & $0,7(1)$ & $0,6(1)$ & $0,2(4)$ & $0,3(3)$ & $5,4(3)$ \\
CSL Araranguá & $0,4(5)$ & $0,4(3)$ & $0,5(3)$ & $0,1(5)$ & $0,2(4)$ & $0,1(4)$ & $5,3(4)$ \\
CASEP Criciúma & $0,6(3)$ & $0,6(2)$ & $0,7(1)$ & $0,5(2)$ & $0,7(1)$ & $0,9(1)$ & $4,5(5)$ \\
CASEP Concórdia & $0,6(3)$ & $0,4(3)$ & $0,7(1)$ & $0,4(3)$ & $0,5(2)$ & $0,0(5)$ & $4,5(5)$ \\
CSL Criciúma & $0,4(5)$ & $0,4(3)$ & $0,5(3)$ & $0,1(5)$ & $0,2(4)$ & $0,1(4)$ & $4,3(6)$ \\
CASEP Blumenau & $0,4(5)$ & $0,4(3)$ & $0,6(2)$ & $0,1(5)$ & $0,0(5)$ & $0,0(5)$ & $4,0(7)$ \\
CASEP Rio do Sul & $0,3(6)$ & $0,0(4)$ & $0,2(6)$ & $0,3(4)$ & $0,7(1)$ & $0,1(4)$ & $3,8(8)$ \\
CASEP São José do Cedro & $0,3(6)$ & $0,4(3)$ & $0,5(3)$ & $0,3(4)$ & $0,3(3)$ & $0,1(4)$ & $3,5(9)$ \\
CASEP Xanxerê & $0,6(3)$ & $0,4(3)$ & $0,5(3)$ & $0,6(1)$ & $0,2(4)$ & $0,1(4)$ & $3,3(10)$ \\
CASEP Joaçaba & $0,4(5)$ & $0,4(3)$ & $0,4(4)$ & $0,4(3)$ & $0,2(4)$ & $0,1(4)$ & $3,3(10)$ \\
CASEP Curitibanos & $0,8(1)$ & $0,4(3)$ & $0,0(7)$ & $0,1(5)$ & $0,3(3)$ & $0,0(5)$ & $3,3(10)$ \\
CSL Blumenau & $0,4(5)$ & $0,4(3)$ & $0,0(7)$ & $0,5(2)$ & $0,0(5)$ & $0,0(5)$ & $3,0(11)$ \\
CASEP Tubarão & $0,2(7)$ & $0,8(1)$ & $0,0(7)$ & $0,4(3)$ & $0,5(2)$ & $0,0(5)$ & $2,5(12)$ \\
CSL Concórdia & $0,7(2)$ & $0,4(3)$ & $0,5(3)$ & $0,5(2)$ & $0,0(5)$ & $0,0(5)$ & $2,0(13)$ \\
PAI & $0,8(1)$ & $0,6(2)$ & $0,2(6)$ & $0,3(4)$ & $0,0(5)$ & $0,3(3)$ & $1,3(14)$ \\
CSL Chapecó & $0,5(4)$ & $0,4(3)$ & $0,5(3)$ & $0,1(5)$ & $0,0(5)$ & $0,1(4)$ & $1,1(15)$ \\
\hline
\end{tabular}

1. Índice de Integração em Rede; 2. Índice de Presença Profissional;

3. Índice de Utilização dos Instrumentos Profissionais; 4. Índice de Organização do Atendimento; 5. Índice de Escolaridade; 6. Índice de Atendimento à Saúde; 7. Índice Geral de Direitos.

Fonte: Simões, 2012 
Não será possível realizar uma análise de todas as Unidades, discutindo cada índice em particular. Chamo atenção, entretanto, para quatro Unidades: CSL Florianópolis (maior índice de direitos); CASEP Criciúma (bons resultados); PAI (única Unidade gerenciada pelo Estado que consta na pesquisa) e CSL Chapecó (pior índice de direitos).

CSL é a Unidade que tem maior índice geral de direitos. Ao se analisar os demais índices dessa Unidade, é possível verificar que esta não se encontra bem rankeada ao se observar os demais índices. $O$ índice de integraçáo em rede é baixo (apenas o sexto em sete possíveis), o índice de presença de profissionais também náo é alto (o terceiro em quatro possíveis), os profissionais da Unidade também não estão entre os que mais utilizam os instrumentos profissionais (a Unidade está no quinto posto entre sete possíveis) e a escolarizaçáo também náo é o forte da Unidade (ela ocupa o quarto posto entre cinco possíveis). Por outro lado, a Unidade apresenta boa organizaçáo do atendimento (segundo posto entre cinco) e bom atendimento à saúde (segundo posto em cinco). Portanto, mesmo a Unidade com maior índice de garantia de direitos precisa melhorar nos itens que se encontram nas últimas posiçóes do ranking, no conjunto das Unidades estudadas.

CASEP Criciúma destaca-se por apresentar ótimos índices. Entretanto, seu índice de garantia de direitos (índice geral de direitos) náo acompanha os demais. Nos seis índices considerados (excetuando-se o de direitos), seu pior rankeamento é a terceira posição no índice de integração em rede. Nos demais, a Unidade encontra-se sempre entre a primeira e a segunda posiçóes. Esta é, por exemplo, a Unidade que mais garante os direitos de educação e saúde. Ainda assim, quatro outras Unidades conseguem garantir mais direitos que CASEP Criciúma.

PAI é a única Unidade administrada pelo Estado. Seus resultados demonstram que, entre as dezoito consideradas, somente uma garante menos direitos que ela (posição quatorze no ranking, entre quinze posiçóes possíveis). Educação e saúde são pontos fracos da Unidade (posiçáo cinco entre cinco possíveis e posição três em cinco possíveis, respectivamente), além da utilização de instrumentos profissionais (posição seis em sete possíveis) e organização do atendimento (posição quatro em cinco). Entretanto, a Unidade tem a maior integração em rede (posição um do ranking) e tem boa presença de profissionais (posiçáo dois do ranking). 
CSL Chapecó é a Unidade que apresentou resultados nas posiçóes intermediárias e inferiores dos rankings considerados. Diferente do PAI, a Unidade em foco não apresentou nenhum resultado que contrabalançasse os índices fracos identificados. Além de apresentar o pior índice de garantia de direitos, a Unidade também apresentou: os piores índices de organização do atendimento e escolarizaçáo; as penúltimas posiçóes em presença de profissionais e atendimento à saúde; e posiçóes intermediárias em integração em rede e utilizaçáo de instrumentos profissionais.

A análise realizada vale-se do posicionamento no ranking para identificar o potencial de cada Unidade. Entretanto, é preciso considerar que esta metodologia tem como objetivo identificar as distinçóes entre as Unidades, mensurando suas diferenças. Deve-se considerar, outrossim, que, para todos os índices considerados, o resultado esperado para cada Unidade era o valor máximo do índice (ou seja, 1 [um]), o que significaria que as Unidades estáo integradas em rede com todas as instituiçóes pesquisadas; que há todos os profissionais previstos nas Unidades; que estes profissionais valem-se de todos os instrumentos profissionais que lhes sáo disponíveis; que eles utilizam-se de todas as formas de organizaçáo do atendimento possíveis; e que todos os direitos dos adolescentes sáo contemplados. Portanto, o rankeamento demonstra, não só as diferenças entre as Unidades, mas o quanto elas se distanciam do que está estabelecido na resolução do Conanda e na Lei do Sinase como partes necessárias do atendimento socioeducativo.

\section{Referências}

CONANDA. Sistema Nacional de Atendimento Socioeducativo. Brasília: Secretaria de Direitos Humanos, 2006.

COSTA, A. C. G. (Coord.). As Bases Éticas das açóes socioeducativas. Brasília: SDH, $2006 a$.

Os Regimes de atendimento no Estatuto da Criança e do Adolescente. Brasília: SDH, 2006b.

Por uma política de execuçáo das medidas socioeducativas. Brasília: SDH, 2006c.

Socioeducação. Brasília: SDH, 2006d.

KLOSINSKI, G. Adolescência Hoje: situações e conflitos. Petrópolis: Vozes, 2006. 
MATTAR, L. D. Exercício da Sexualidade por Adolescentes em ambiente de Privação de Liberdade. Cadernos de Pesquisa, v. 38, n. 133, p. 61-95, 2008.

MIRANDA, H. Criança e Adolescente: do tempo da assistência à era dos direitos. Recife: UFPE, 2010.

RAMIDOFF, M. L. Sinase - Sistema Nacional de Atendimento Socioeducativo. Comentários à Lei n. 12.594, de 18 de janeiro de 2012. São Paulo: Saraiva, 2012.

SIMÓES, P. Garantindo Direitos? Florianópolis: Pró-Reitoria de Extensão/UFSC, 2012.

VIEIRA, C. E. Da Categoria Menor à Categoria Criança e Adolescente: o advento da Doutrina Jurídica da Proteção Integral. In: RIFIOTIS, T.; RODRIGUES, T. H. (Org.). Educação em Direitos Humanos. Santa Catarina: EDUFSC, 2008.

VOLPI, M. (Org.) O Adolescente e o Ato Infracional. 9. ed., Sáo Paulo: Cortez, 2011.

ZAMORA, M. H. (Org.) Para Além das Grades: elementos para a transformaçáo do sistema socioeducativo. Rio de Janeiro: PUC-RJ; Sáo Paulo: Loyola, 2005.

Recebido em: 08.09.2013

Aprovado em: 11.02.2014

\section{Guaranteeing rights? Study of Santa Catarina socioeducative system}

\section{Abstract}

The Law 12.594 that established SINASE was promulgated in January of 2012. The Law, associated to the Ecriad (1990) and CONANDA's Normatization (2006), marks a new step of consolidation in rights from youth in liberty privation. These efforts broke the menorista point of view and established, to the youth in regime of liberty privation and semi liberty privation, the same rights for those in liberty. So, in $2011-12$, the Socioeducative System of Santa Catarina organized a research whose issue was how much the youth's right was observed at the Units of System. It was researched 18 of the 24 units in the System. The outcomes presented show how far is the law from the institutional reality of the social rights conferred to the youth.

Keywords: Youth in Liberty Privation. Guarantee rights. Socioeducation. 